\title{
Optimization of Process Parameters by Response Surface Methodology for Methylene Blue Removal Using Cellulose Dusts
}

\author{
Seyed Hassan Sharifi ${ }^{{ }^{*}}$, Saltanat Archin ${ }^{\text {a }}$, Ghasem Asadpour ${ }^{\text {a }}$ \\ ${ }^{a}$ Wood and Paper Science Department, Faculity of Natural Resources, Sari Agricultural Sciences and Natural Resource University, Mazandaran, Iran.
}

Received 20 January 2018; Accepted 28 February 2018

\begin{abstract}
This study was aimed to use Cellulose dusts (CD) produced in drying section of paper mills of paper making industry as a potential adsorbent to remove methylene blue (MB) dye from aqueous solution. The adsorbent was characterized by scanning electron microscopy and Fourier transform infrared spectrometer and X-ray Diffraction. The influences of the effective parameters including $\mathrm{pH}$ solution, adsorbent dosage, initial MB concentration, and contact time were optimized by CCD which stands for central composite design. The influence of these parameters on the adsorption capacity was analyzed using the batch process. The accuracy of the equation that is produced by CCD was affirmed by the variance analysis and also by calculating the correlation coefficient that connects the predicted and the empirical values of the percentage of removed MB dye. Maximum removal percentage of MB dye $(98.05 \%)$ which obtained at $\mathrm{pH} 9.84$, adsorbent dosage $4.38 \mathrm{~g} \mathrm{~L}^{-1}$, MB concentration $75.50 \mathrm{~g} \mathrm{~L}^{-1}$ and time $208.13 \mathrm{~min}$. Freundlich, Temkin, Harkins-Jura and Langmuir isotherms are used to analyze the empirical data. Results revealed that the data is in a satisfying agreement with the Freundlich isotherm $(R 2=0.99)$. Pseudo-first order, Pseudo-second-order, Elovich and Intraparticle diffusion models were used to fit the kinetic data and it is found out that MB dye's adsorption onto CD has a good agreement with the pseudosecond-order kinetic model. The results showed that $\mathrm{CD}$ can be an efficient and low-cost adsorbent for methylene blue adsorption.
\end{abstract}

Keywords: Cellulose Dusts; Adsorption; Optimization; Isotherm; Kinetics.

\section{Introduction}

Industrial activities generate large volume of wastewater containing hazardous inorganic (metals) or organic (microbes, dyes/pigments) species. Dye contaminated wastewater is one of the visual significant pollution generated from plastic, cosmetic, paper and pulp, textile, distilleries and tanneries industries [1].

Dyes usually have complex aromatic molecular structures which make them more stable and difficult to biodegrade. However, their disposal in water bodies exhibit adverse effect to the aquatic and human life by creating eutrophication, mutagenic, carcinogenic effects, dysfunction of the organs, also having effect on aquatic ecosystem by preventing sunlight from reaching into the stream $[2,3]$.

Azo dyes are the biggest type among several other chromogenic materials that are released by many industries [4, 5]. They are more than $70 \%$ of all commercial dyes which makes them to be undisputed major synthetic dye. They are characterized by one or more azo groups $(\mathrm{N}=\mathrm{N})$ as chromophore, with aromatic containing groups and other functional groups such as $-\mathrm{OH}$ and $-\mathrm{SO}_{3} \mathrm{H}[6,7]$. Based on the chromophore group, 20-30 different groups of dyes are pollutant [8]. Methylene blue (MB) is one of major basic dyes, which is used for coloring purposes very much. This dye can cause permanent injury to the human eye, irritation to the gastrointestinal tract, and skin irritation. MB is a common pollutant

* Corresponding author: h.sharifi@sanru.ac.ir.

dol http://dx.doi.org/10.28991/cej-0309121

$>$ This is an open access article under the CC-BY license (https://creativecommons.org/licenses/by/4.0/).

(C) Authors retain all copyrights. 
material in textile wastewater and is frequently used in dye houses and textile industries. The MB's removal from aqueous solutions by applying substances that cost low (e.g. agricultural wastes) has been researched by others [9-11].

This dye as a thiazine cationic dye is selected as a model organic (heterocyclic aromatic) compound because it is known to adsorb more easily onto solids and in order to evaluate the behavior of sorbent for the removal of organic pollutants from its aqueous solutions [12].

There are numerous techniques available for dye removal from wastewater like membrane separation, $[13,14]$ degradation by micro-organisms and photochemical, [15] chemical oxidation, [16] anion exchange resins, [17] coagulation, [18] flocculation and adsorption [19].

Adsorption on the surface of the solids is getting increasing attraction in the field among other approaches since its price is lower and the activated adsorption significantly effects the dyes and pigments' removal and also other organic and inorganic pollution [20].

Processes involving adsorption are applied in different domains including medicine, environment, oil and gas, etc. for removing of pesticides, storage, metals, dyes, and oil spillage control [21]. For the removal of phenols, dyes, pesticides or other organic substances, the majority of systems apply carbon as an adsorbent because it has a remarkable ability in adsorption. Nonetheless, its common apply is limited because of its cost and its problem with regeneration [22].

Lately, various agricultural waste and residues are analyzed with the purpose of using them as adsorbent for removing dyes from waste waters due to fact that they cost low, their toxicity is low and they are easily available [23].

Cellulose dusts (CD) produced in drying section of paper mills has no economic use and value, and they are removed from the production cycle. Thus, these wastes can be applied as a low-cost and plentiful adsorbent for removing dyes from waste water.

Response surface methodology (RSM) is a sequential procedure and collection of mathematical and statistical techniques which is useful for mathematical modeling and examination of problems. During modeling, the first-order model is appropriate when we are at a point on the response surface that is distant from the optimum operating conditions and a little curvature in the system is seen [24, 25]. It leads the experiments quickly and efficiently along a path of enhancement toward the general vicinity of the optimum. After locating the region of the optimum a more elaborate second-order model, may be used to analyze and locate the optimum. Among the RSM designs, central composite design (CCD) is the most popular method due to its simple structure and good efficiency [26].

On the basis of primary data obtained experimentally, all the affecting variables including the dose of adsorbent, contact time, $\mathrm{pH}$, and initial concentration of $\mathrm{MB}$ dye collectively have been optimized by statistical experimental design; RSM.

The objective of the present study was to investigate the optimum condition for maximum adsorption of MB dye on Cellulose dusts. The CCD model was used for precisely finding the role of individual process parameters and also optimization of process variables. Moreover, Cellulose dusts was characterized by using FTIR, SEM and XRD.

In this study, we studied the $\mathrm{CD}$ produced in drying section of paper mills as a potential adsorbent for the removal of dyes from wastewater. The objective of the present study was to investigate the optimum condition for maximum adsorption of MB dye on cellulose dusts. The research is classified to some section viz. (1) preparation of cellulose dust and defining its properties by XRD, FTIR and SEM; (2) optimization by CCD combined with RSM; (3) to specify how four independent parameters affect (Parameters including time, the dose of adsorbent, initial concentration of MB, initial $\mathrm{pH})$ and also to understand their interactions on removing $\mathrm{MB}(\%)$; and (4) to research about adsorption isotherms and kinetics model.

\section{Experimental and Methods}

\subsection{Materials and Chemicals}

Cellulose dusts was prepared from Mazandaran Wood and Paper Industries (MWPI) in Iran, Co., Ltd (Figure 1). Distilled water was used to wash it a few times and therefore purify it. It was then dried up to the point that there was no difference in its weight. Then it was applied as raw material. 


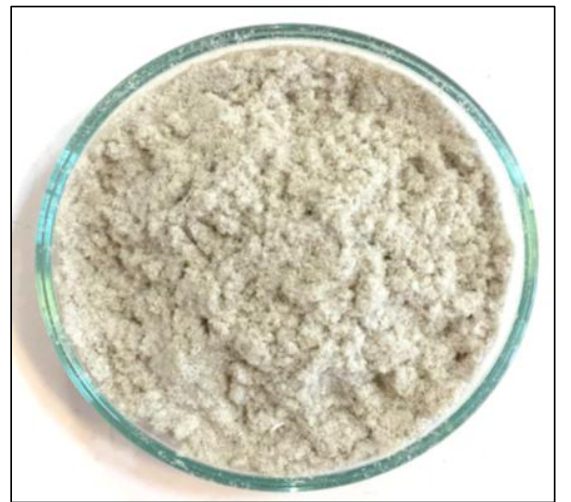

Figure 1. Photograph of cellulose dusts powder

Methylene blue (MB) (its chemical formula is: $\mathrm{C}_{16} \mathrm{H}_{18} \mathrm{CIN}_{3} \mathrm{~S} .3 \mathrm{H}_{2} \mathrm{O}$ and its molecular weight is equal to $319.86 \mathrm{~g}$ $\mathrm{mol}^{-1}$; the analysis at wavelength $664 \mathrm{~nm}$; Figure 2 shows the chemical structure), $\mathrm{NaOH}$ (with $99 \%$ purity) and $\mathrm{HCl}$ (with 37\% purity) were purchased from Merk (Germany). All solutions were prepared using distilled water. All chemicals were reagent grade and were used without further treatment.

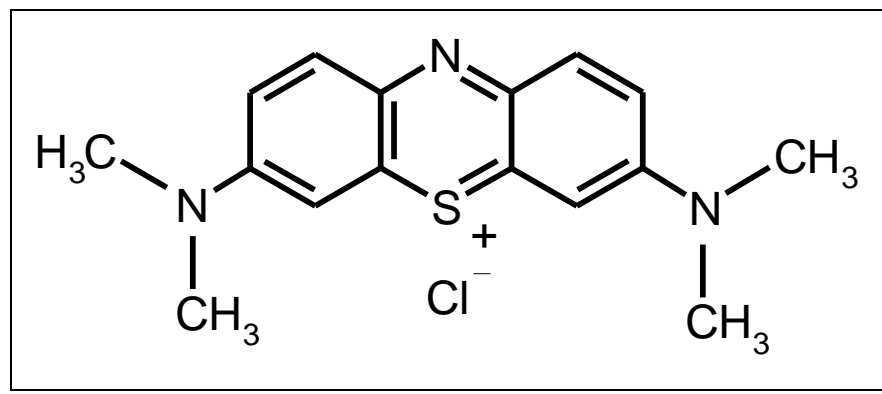

Figure 2. Chemical structure of methylene blue

\subsection{Batch Adsorption Studies}

MB colored solution was prepared and diluted with the desired concentrations (20-100 mg L $\left.\mathrm{L}^{-1}\right)$. Experiments were conducted to investigate the effect of $\mathrm{pH}$ (4-12), absorbent dose (1-5 g L $\left.\mathrm{g}^{-1}\right)$, time (30-270 min) and constant temperature on methylene blue adsorption by CD.

To measure moisture content, $1 \mathrm{~g}$ of this CD dried in an oven for 24 hours at a temperature of $103{ }^{\circ} \mathrm{C}$ and then the rest of the paper wastes stored in the bottle to use. In each experiment, a certain amount of adsorbent was added to a certain amount of dye solution and initial $\mathrm{pH}$ values were modified before by either $\mathrm{HCl}$ or $\mathrm{NaOH}$, at $0.1 \mathrm{~N}$.

The solution was mixed at different times and room temperature by orbital shaker $(200 \mathrm{rpm})$. The solid phase was then separated by centrifugation $(6000 \mathrm{rpm})$ through the liquid. Then, the dye concentration was measured at $664 \mathrm{~nm}$ maximum methylene blue wavelength using a UV-visible spectrophotometer (Cary- Eclipse).

The adsorption isotherms provide information about the distribution of dye molecules within the adsorbent at equilibrium. Generally, adsorption isotherm researches are done with the purpose of correlating the capacity of adsorption and the residual concentration of the adsorbate which exists in the aqueous solution. There are various isotherm equations that are accessible from the literature, four of them were chosen for the research: Harkins-Jura, Temkin, Langmuir and Freundlich Isotherm models. The dynamics of dyes adsorption onto cellulose dusts were analyzed using four different kinetic models: the pseudo first- order, pseudo-second-order, intraparticle diffusion and Elovich models [27-28].

\subsection{Characterization of Adsorbent}

The characterization of Cellulose dust was performed by employing scanning electron microscopy (SEM), X-ray diffraction (XRD) and Fourier transformed infrared spectroscopy (FTIR).

\subsection{Measurement of Adsorption Efficiency}

The standard calibration method was adopted by running a series of standard solutions of the dye. The adsorption efficiency was estimated for the various runs performed using CCD. Following equation was used to obtain the percentage of the dye that has been removed. 


$$
\% \text { Removal }=\frac{C_{o}-C_{t}}{C_{o}} \times 100
$$

Where, $\mathrm{C}_{\mathrm{o}}$ represents the initial concentration in $\mathrm{mg} \mathrm{L}^{-1}$ and $\mathrm{C}_{\mathrm{t}}$ represents the concentration in $\mathrm{mg} \mathrm{L}^{-1}$ remaining in the solution after time t. The adsorption capacity of the synthesized nanocomposites was calculated by the given equation.

$$
\% q_{e}=\frac{\left(C_{o}-C_{e}\right) \times V}{W}
$$

$\mathrm{C}_{\mathrm{o}}$ stands for the initial concentrations of the dye in $\mathrm{mg} \mathrm{L}^{-1}$ and $\mathrm{C}_{\mathrm{e}}$ represents the equilibrium concentrations of the dye in $\mathrm{mg} \mathrm{L}^{-1}$. V stands for the volume in liters of the solution and $\mathrm{W}$ represents the mass in grams of the adsorbent [40].

\subsection{Central Composite Design}

A standard response surface methodology (RSM) design known as central composite design (CCD) was used to study the parameter for adsorption of MB with Cellulose dusts. The CCD is apposite to be fit in a quadratic surface to get the Optimum Operating Parameters (OOP) and to also assess the influence of parameters and the interactions of them [29]. This design encompasses bi level factorial design with at least one central point in the experimental conditions and with axial points also termed as star points. To improve the accuracy, increased number of central points are often used that minimizes a great deal of experimental error. The orthogonality and rotatability is ensured by the value of a that can be calculated using the following equation.

$$
\alpha=\sqrt[4]{2^{\mathrm{f}}}
$$

The required experimental runs are calculated using the following Equation.

$$
N=2^{f}+2 f+N_{o}
$$

In above equation, $\mathrm{f}$ represents the number of variables to be studied, $2 \mathrm{f}$ indicates factorial points, $2 \mathrm{f}$ denotes the axial points and No is the replicates of center points [30].

In the current studies, CCD of 4 variable levels was employed having 5 central points. Alpha value of 2.0 was selected for the design. The number of runs were evaluated to be 30. The CCD along with the corresponding responses is given in Table 1. Each experimental run was conducted and the responses were correlated with four variables using the given quadratic polynomial equation.

$$
y=\beta_{0}+\sum_{i=1}^{4} \beta_{i} x_{i}+\sum_{i=1}^{4} \sum_{i=1}^{4} \beta_{i j} x_{i} x_{j}+\sum_{i=1}^{4} \beta_{i j} x_{i}^{2}
$$

In the above equation, $\mathrm{y}$ represents the anticipated response that is the percentage removal, Xi denote the independent variables. $\beta_{0}, \beta_{\mathrm{i}}, \beta_{\mathrm{ii}}$ and $\beta_{\mathrm{jj}}$ represent the model constant, linear coefficient, quadratic coefficient and the interaction coefficient respectively. Response Surface Methodology is coupled with CCD to evaluate the significant factors and solve multivariate equations to obtain Optimum Operating Parameters. The first or second order polynomial equations are provided in accordance with the empirical responses and also their consequent correlation. The variance analysis (ANOVA) aids in the prominent contribution of experimental parameters and interactions of them. The response surface is described by the 3D graph that is used to predict the Optimum Operating Parameters based on their P-values and Fvalues [30].

\begin{tabular}{|c|c|c|c|c|c|c|}
\hline \multirow{2}{*}{ Factors } & \multirow{2}{*}{ Units } & \multicolumn{3}{|c|}{ Levels } & \multirow{2}{*}{$-\alpha$} & \multirow{2}{*}{$+\alpha$} \\
\hline & & Low (-1) & Central (0) & High (+1) & & \\
\hline (A) $\mathrm{pH}$ & - & 6 & 8 & 10 & 4 & 12 \\
\hline (B) adsorbent dosage & $\mathrm{g} \mathrm{L}^{-1}$ & 2.2 & 3.3 & 4.4 & 1.1 & 5.5 \\
\hline (C) MB Concentration & $\mathrm{mg} \mathrm{L}^{-1}$ & 40 & 60 & 80 & 20 & 100 \\
\hline (D) time & $\min$ & 90 & 150 & 210 & 30 & 270 \\
\hline
\end{tabular}

In the current research work, time, $\mathrm{pH}$, adsorbent dosage, and $\mathrm{MB}$ concentration were taken as the 4 factors. Each of the factors was studied with 5 levels. Table 1 shows the coded and uncoded levels of these independent variables. 30 runs were performed and the removal of MB was taken as the responses (Table 2).

Table 1. Central composite design for four factors with their levels and observed responses 


\section{Result and Discussion}

\subsection{Characterization of Adsorbent}

The SEM micrographs of the CD before MB adsorption (Figure 3a) indicate regular morphology with an external, it reveals the surface texture and porosity of adsorbent. After MB adsorption (Figure 3b), the pores are absent on the surface of MB loaded CD, this change in morphology is due to accumulation of MB on CD surface.
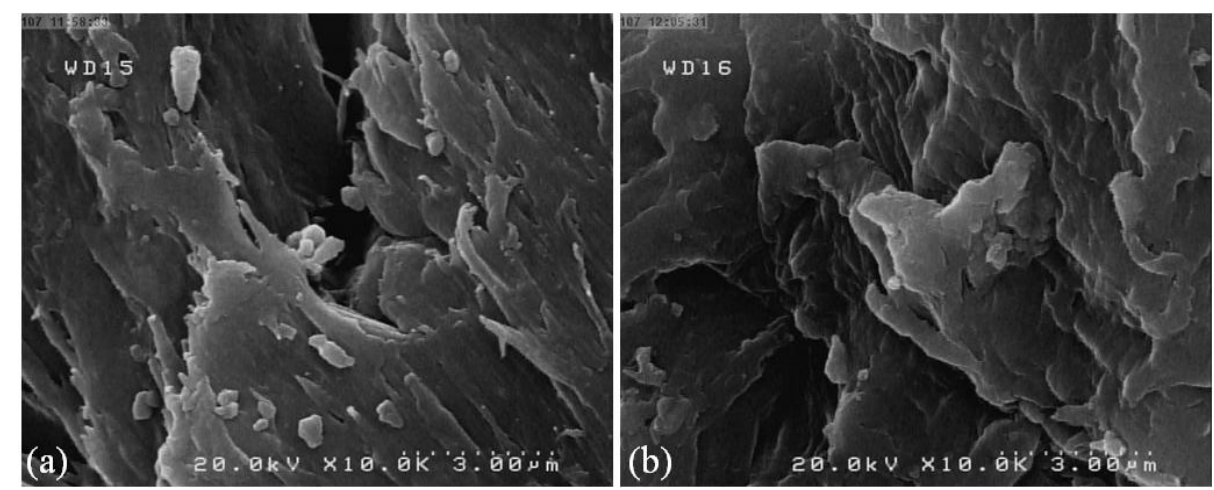

Figure 3. SEM analysis of (a) unloaded CD (b) CD loaded with MB.

X-ray diffraction studies of CD were performed to determine the structure of the adsorbent. The X-ray diffractogram of the CD is shown in Figure 4. The XRD diffractogram indicated that the prominent peaks appeared at $2 \theta$ positions of $15.82,22.30,29.50$ and 36.03. The corresponding values of the Miller indices at these peaks were observed to be (10 1), (002) and (040). These are the two peaks corresponding two different phases in cellulose (I and II) [31]. The CDs were analyzed to contain orthorhombic structure as illustrated in JCPDS-Section 15. The crystal size of cellulose based on the Debeye-Scherrer formula was found to be around $56 \mathrm{~nm}$ in accordance with FWHM which stands for full width at half-maximum of the (002) peak [32].

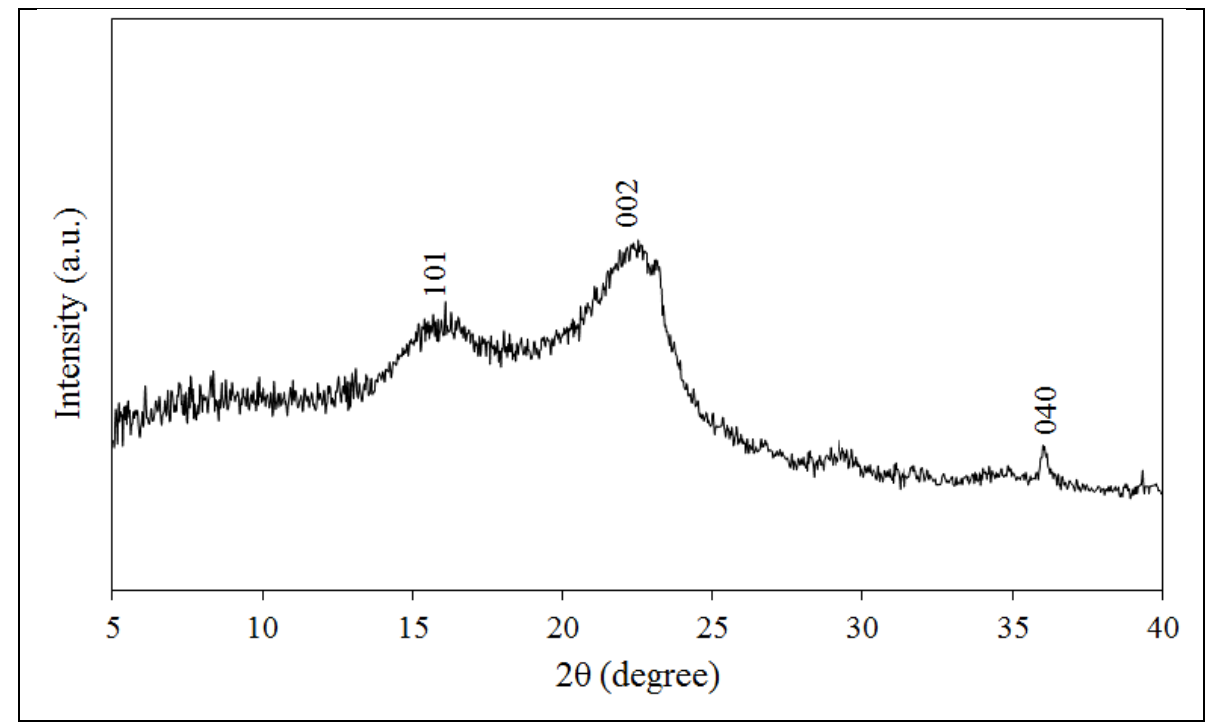

Figure 4. The XRD pattern of CD

FTIR Spectrum of CD before and after adsorption of MB in the range of 650-4000 cm-1 (Figure 5) exhibits characteristic peaks appeared at $3300 \mathrm{~cm}-1$ because of $\mathrm{O}-\mathrm{H}$ group (carboxylic acids, phenols and alcohols) on the surface of adsorbent as in cellulose, pectin and lignin [33, 34]. While the peak at $2900 \mathrm{~cm}-1$ representing CarbonHydrogen distortion in in biomass structure (cellulose, hemicellulose, lignin) [35].

The bands in region $1595 \mathrm{~cm}^{-1}$ and $1504 \mathrm{~cm}^{-1}$ are assigned to $\mathrm{C}=\mathrm{C}$ aromatic stretching of lignin [36]. The bands at $1230 \mathrm{~cm}^{-1}$ and $1025 \mathrm{~cm}^{-1}$ corresponds to C-O stretching vibration of carboxylic acids and alcohols. The band at $896 \mathrm{~cm}^{-}$ ${ }^{1}$ can be due the bending vibration of $\mathrm{C}-\mathrm{H}[37,38]$.

After adsorption of MB, we note that the peaks intensity of O-H $\left(3300 \mathrm{~cm}^{-1}\right), \mathrm{C}-\mathrm{O}\left(1230 \mathrm{~cm}^{-1}, 1025 \mathrm{~cm}^{-1}\right)$ and C-H $\left(2900 \mathrm{~cm}^{-1}\right)$ decreased, these shifts indicate that an interaction was occurred between $\mathrm{MB}$ and these groups. 


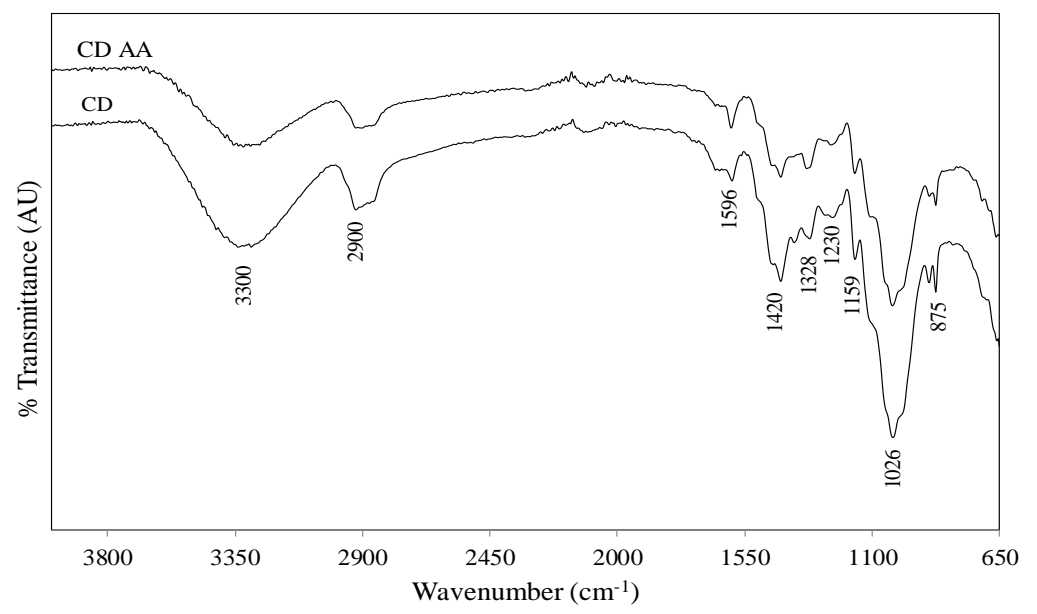

Figure 5. The FTIR spectrums of CD before and after adsorption (CD AA) of MB

\subsection{Response Surface Methodology}

The influences of different parameters such as $\mathrm{pH}(\mathrm{A}), \mathrm{MB}$ initial concentration (B), adsorbent dosage (C) and time (D) on $\mathrm{MB}$ removal percentage by $\mathrm{CD}$ were investigated and optimized. Optimization of MB removal percentage using RSM and CCD was employed to evaluate the interaction among the significant variables and also to determine their optimal values.

Table 2 represents the regression results of the response surface from CCD. Statistical analysis was carried out by fitting experimental data to a general model equation given in Equation 5. An empirical relationship articulated by a second-order polynomial equation with interaction provisos was fitted between the experimental results obtained on the basis of CCD model and the input functional variables. The last equation which is provided for MB dye in terms of actual (natural) parameters is applied which is the form of the transformed model equation in terms of coded and actual factors (Equations 6 and7):

Final equation in terms of actual factors for MB removal

$$
\begin{aligned}
\text { Removal (\%) }= & 0.5533+0.0139 X_{A}+0.0552 X_{B}+0.00285 X_{C}+0.00106 X_{D}-4.823 \\
& \times 10^{-4} X_{A} X_{B}+7.813 \times 10^{-6} X_{A} X_{C}-1.615 \times 10^{-5} X_{A} X_{D}-9.943 \\
& \times 10^{-5} X_{B} X_{C}+7.670 \times 10^{-5} X_{B} X_{D}-2.604 \times 10^{-6} X_{C} X_{D}-3.411 \\
& \times 10^{-4} X_{A}^{2}-0.00598 X_{B}^{2}-1.9349 \times 10^{-5} X_{C}^{2}-2.636 \times 10^{-6} X_{D}^{2}
\end{aligned}
$$

Final equation in terms of coded factors for MB removal

$$
\begin{aligned}
\text { Removal (\%) }= & 0.95+9.875 \times 10^{-3} X_{A}+0.019 X_{B}+4.375 \times 10^{-3} X_{C}+0.023 X_{D} \\
& -1.062 \times 10^{-3} X_{A} X_{B}+3.125 \times 10^{-4} X_{A} X_{C}-1.937 \times 10^{-3} X_{A} X_{D}-2.187 \\
& \times 10^{-3} X_{B} X_{C}+5.063 \times 10^{-3} X_{B} X_{D}-3.125 \times 10^{-4} X_{C} X_{D}-1.365 \\
& \times 10^{-3} X_{A}^{2}-7.240 \times 10^{-3} X_{B}^{2}-7.740 \times 10^{-3} X_{C}^{2}-9.490 \times 10^{-3} X_{D}^{2}
\end{aligned}
$$

Table 2. Design matrix for the central composite designs

\begin{tabular}{cccccc}
\hline \multirow{2}{*}{ Run No. } & \multicolumn{3}{c}{ Experimental factors } & MB Removal (\%) \\
\cline { 2 - 4 } & A & B & C & D & \\
\hline 2 & 6 & 4.4 & 80 & 210 & 0.965 \\
3 & 8 & 3.3 & 60 & 150 & 0.953 \\
4 & 10 & 2.2 & 80 & 90 & 0.91 \\
5 & 8 & 3.3 & 20 & 150 & 0.895 \\
6 & 12 & 3.3 & 60 & 150 & 0.97 \\
7 & 8 & 3.3 & 100 & 150 & 0.939 \\
8 & 10 & 4.4 & 80 & 90 & 0.92 \\
9 & 6 & 4.4 & 40 & 90 & 0.91 \\
10 & 8 & 1.1 & 60 & 150 & 0.87 \\
11 & 8 & 5.5 & 60 & 150 & 0.968 \\
12 & 8 & 3.3 & 60 & 150 & 0.945 \\
13 & 8 & 3.3 & 60 & 150 & 0.95 \\
& 10 & 4.4 & 40 & 90 & 0.925
\end{tabular}




\begin{tabular}{cccccc}
14 & 10 & 4.4 & 80 & 210 & 0.972 \\
15 & 6 & 4.4 & 80 & 90 & 0.896 \\
16 & 4 & 3.3 & 60 & 150 & 0.915 \\
17 & 8 & 3.3 & 60 & 150 & 0.949 \\
18 & 6 & 4.4 & 40 & 210 & 0.959 \\
19 & 10 & 4.4 & 40 & 210 & 0.968 \\
20 & 10 & 2.2 & 80 & 210 & 0.927 \\
21 & 6 & 2.2 & 80 & 90 & 0.885 \\
22 & 6 & 2.2 & 40 & 90 & 0.875 \\
23 & 6 & 2.2 & 40 & 210 & 0.913 \\
24 & 8 & 3.3 & 60 & 270 & 0.96 \\
25 & 8 & 3.3 & 60 & 150 & 0.945 \\
26 & 8 & 3.3 & 60 & 30 & 0.86 \\
27 & 10 & 2.2 & 40 & 210 & 0.935 \\
28 & 6 & 2.2 & 80 & 210 & 0.917 \\
29 & 10 & 2.2 & 40 & 90 & 0.89 \\
30 & 8 & 3.3 & 60 & 150 & 0.949 \\
\hline
\end{tabular}

The statistical significance of quadratic model at $95 \%$ confidence level was tested by ANOVA results, which are capable of modeling to fit the response parameters. The variables that are presented in ANOVA (Table 3 ) were the error terms, the main effects and the interaction effects. The amounts of $F$ and $p$ were applied to stand for the significance of these parameters in the quadratic model. SS which stands for the sum of squares and DF which stands for the degrees of freedom and MS which stands for the mean squares were computed and in accordance with that the amount of F was gained by dividing the amount of MS which is related to each term and the amount of MS that is gained by dividing SS by DF.

In the quadratic model, the F value of 20.516 indicated that the model was statistically significant. The $\mathrm{p}$ value of less than 0.0001 confirm high significancy of model, while its accuracy was confirmed by its high determination of coefficient $\mathrm{R}^{2}$. In the present study, the value of $\mathrm{R}^{2}=0.9504$ indicated that $4.96 \%$ of the total variables were not explained by the model. The amount of the adjusted determination coefficient $\left(\mathrm{R}^{2}\right.$ adj $)$ was 0.9040 has reasonable agreement with observed $\mathrm{R}^{2}$.

Table 3. Analysis of variance (ANOVA) for the response surface quadratic model

\begin{tabular}{cccccc}
\hline Source & Sum of Squares & DF & Mean Square & F value & P value \\
\hline Model & 0.0289 & 14 & 0.002066 & 20.516 & $<0.0001$ \\
A-pH & 0.00234 & 1 & 0.002340 & 23.243 & 0.0002 \\
B- adsorbent dosage & 0.00878 & 1 & 0.008779 & 87.179 & $<0.0001$ \\
C-concentration of MB & 0.000459 & 1 & 0.000459 & 4.5621 & 0.0496 \\
D-time & 0.012376 & 1 & 0.012376 & 122.91 & $<0.0001$ \\
AB & $1.806 \times 10^{-5}$ & 1 & $1.806 \times 10^{-5}$ & 0.1794 & 0.6779 \\
AC & $1.563 \times 10^{-6}$ & 1 & $1.563 \times 10^{-6}$ & 0.0155 & 0.9025 \\
AD & $6.006 \times 10^{-5}$ & 1 & $6.006 \times 10^{-5}$ & 0.5965 & 0.4519 \\
BC & $7.656 \times 10^{-5}$ & 1 & $7.656 \times 10^{-5}$ & 0.7603 & 0.397 \\
BD & $4.101 \times 10^{-4}$ & 1 & $4.101 \times 10^{-4}$ & 4.0723 & 0.0618 \\
CD & $1.563 \times 10^{-6}$ & 1 & $1.563 \times 10^{-6}$ & 0.0155 & 0.9025 \\
A $^{2}$ & $5.107 \times 10^{-5}$ & 1 & $5.107 \times 10^{-5}$ & 0.5072 & 0.4873 \\
B $^{2}$ & 0.00144 & 1 & 0.00144 & 14.277 & 0.0018 \\
C $^{2}$ & 0.00164 & 1 & 0.00164 & 16.317 & 0.0011 \\
$\mathrm{D}^{2}$ & 0.00247 & 1 & 0.00247 & 24.529 & 0.0002 \\
Residual & 0.00151 & 15 & 0.0001 & - & - \\
Lack of Fit & 0.001463 & 10 & 0.0001463 & 15.399 & 0.0038 \\
Pure Error & $4.75 \times 10^{-5}$ & 5 & $9.5 \times 10^{-6}$ & - & -
\end{tabular}




\begin{tabular}{cccccc} 
Cor Total & 0.03043 & 29 & - & - & - \\
Std. dev. & 0.0100 & - & R-squared & - & 0.9504 \\
C.V. $\%$ & 1.0815 & - & Adjusted R-squared & - & 0.9040 \\
Mean & 0.9278 & - & Predicted R-squared & - & 0.7209 \\
PRESS & 0.0085 & - & Adequate Precision & - & 15.996 \\
\hline
\end{tabular}

The lack of fit term is actually non-significant and shows that quadratic model is valid for explanation of experimental work. Table 3 represents that PRESS which stands for the prediction error sum of squares, gives a fine residual scaling and also reveals that sufficient precision (signal to noise ratio) must be higher than 4 to construct desirable. Thus, in the quadratic model for MB's removal process, the ratio of 15.996 indicate an adequate signal for the model to be used to navigate the design space $[39,40]$.

Figure 6a shows the predicted versus actual graph for MB removal percentage, which indicated actual values were distributed relatively close to the straight line and denote. This indicated that the quadratic model was needed for estimating the percentage of the optimized removal of MB under empirical factors.

As shown in Figure 6b (normal probability plot), the normality assumption was satisfied as the residual plot approximated along a straight line. The plot of studentized residuals versus run number was tested and shown in Figure $6 \mathrm{c}$. The residuals were distributed in a random manner near \pm 3.0 , which show high efficiency of model for well presentation explanation of real data.
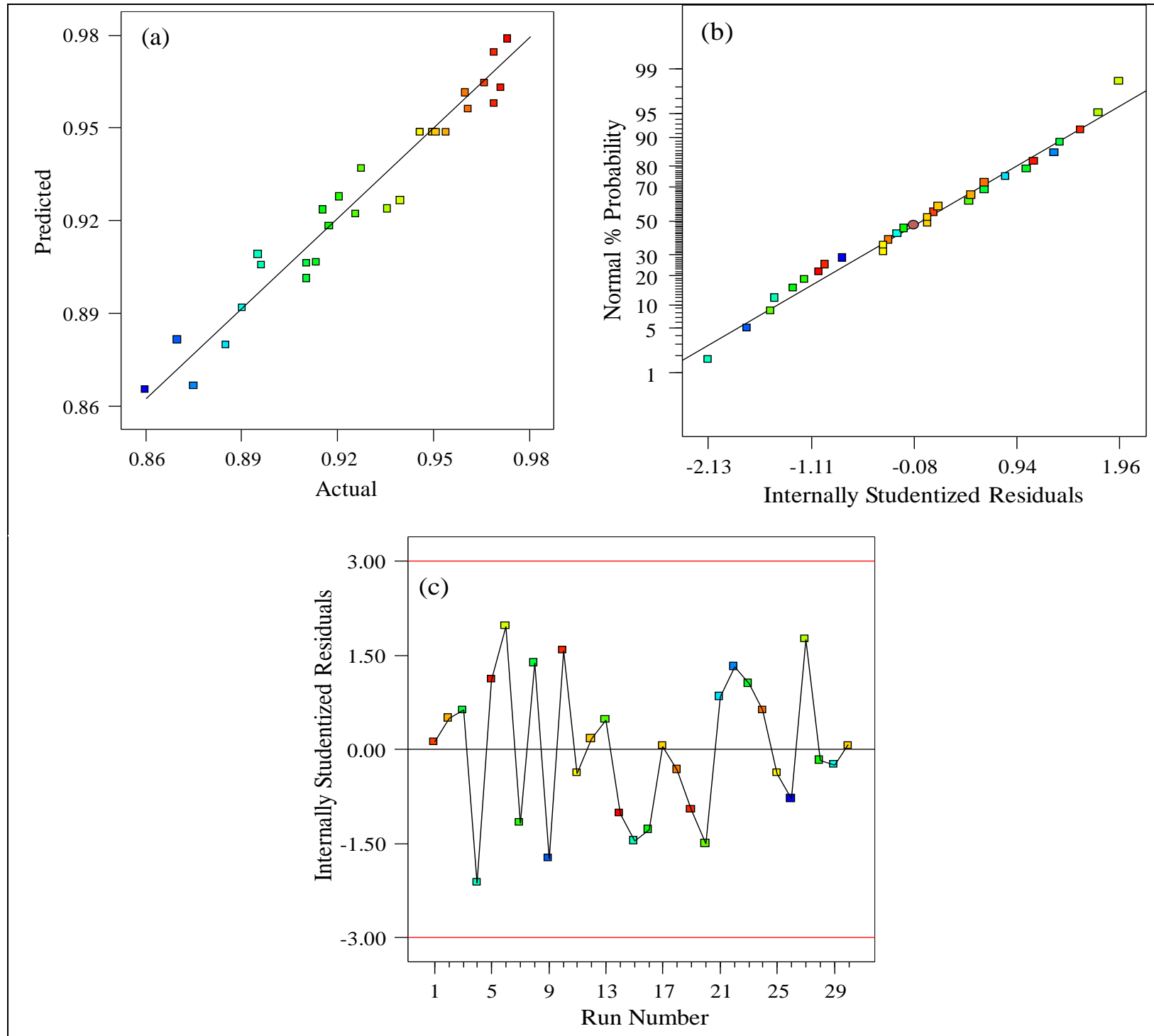

Figure 6. Predicted versus experimental data (a) Normal probability plot of residuals; (b) Internally studentized residual and run; (c) Plots for removing MB 


\subsubsection{Effect of Process Variables on MB Removal}

Based on the data from Table 3, the mean effect plots are displayed in Figure 7. At the time that the response is at its biggest possible amount, the system in these experiments is optimized. It can be observed that $\mathrm{pH}$, adsorbent dosage, concentration of $\mathrm{MB}$ and time have positive impact on the MB removal. According to Table 4, adsorbent dosage is has the most influence as an individual parameter on MB removal $(\mathrm{F}=87.18, \mathrm{p}<0.0001)$.

In the case of adsorbent dosage and time an obvious increment in MB removal is observed by increasing the adsorbent dosage and time. Furthermore, the MB removal was almost unchanged by increasing the MB concentration. Considering the $\mathrm{pH}, \mathrm{MB}$ removal was enhanced by increasing this factor. At low high level of $\mathrm{X}_{\mathrm{A}}, \mathrm{X}_{\mathrm{B}}$ and low level of $\mathrm{X}_{\mathrm{C}}$ with increasing time to upper level, MB removal went higher.

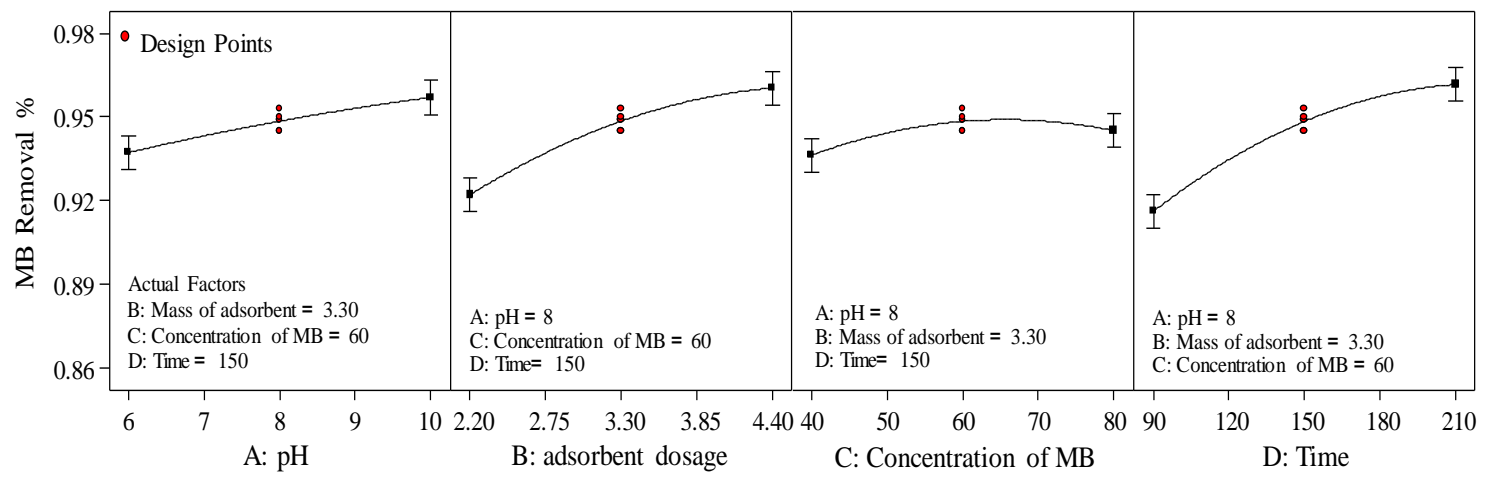

Figure 7. Major effects of each parameter on MB removal

\subsubsection{D Response Surface Plot}

$3 \mathrm{D}$ response surface plots for the measured responses were constructed to better find out about the impacts of independent parameters and interactions of them on the dependent ones. The interaction between the corresponding parameters was negligible when a circular 3D response of the surfaces was found. Further, elliptical or saddle natures of the plot indicate that the interaction between the corresponding variables was significant [41]. Furthermore, parallel lines suggest that there was no significant interaction. In 3D response plots, the upper horizontal axis represents the dependent variable. Response surface methodology (RSM) was applied by considering all the significant interactions among variables in the CCD to find the most important effects. The 3D graphs correspond to MB removal percentage, which describe their variation against the parameters that were plotted at optimum values of others factors and their curvatures is proportional with presence of significance interaction among the variables.

Figure 8 demonstrates that the time and dose of the adsorbent highly affect the MB removal percentage and its bigger amount at higher time especially at high amount of adsorbent was found. Effect of higher dosage of adsorbent probably due to larger reactive surface area and functional group which are sufficient for complexation and binding MB.

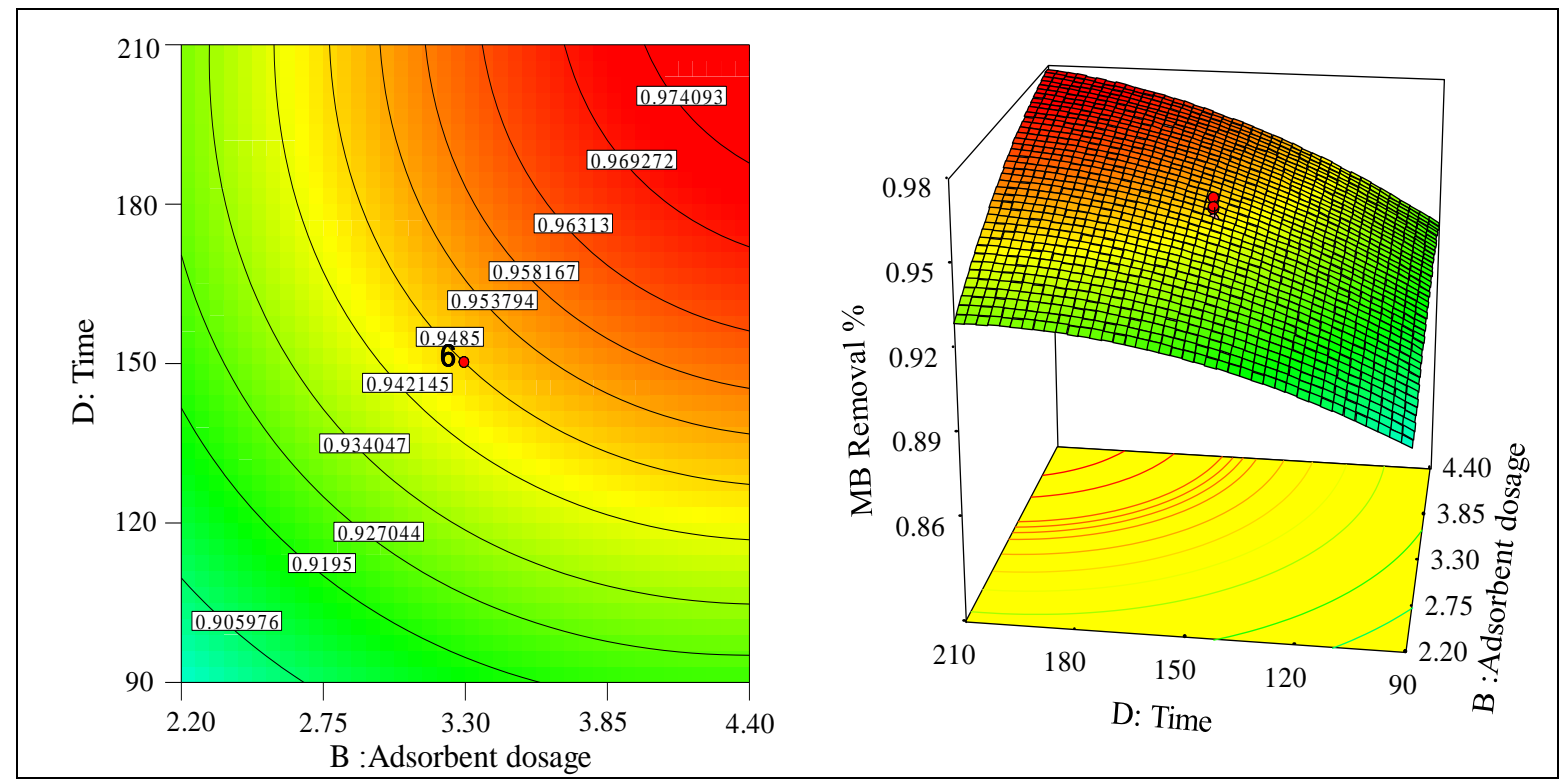

Figure 8. Response surface (left) and contour (right) plots for the combined effects of adsorbent dosage and time on the MB removal 
Figure 9 shows the effect of time and initial MB concentration on MB removal show that removal rate at beginning of the process is rapid because of high available surface area and vacant site of adsorbent, while their subsequent saturation is proportional with reduction in signal. Although the actual amount of MB at higher initial MB concentration, probably due to saturation of reactive sites or increasing the repulsive force between the adsorbed MB and bulk molecules lead to reduction in the percentage of removal [42]. The fact that the removal percentage of MB is greatly dependent to its initial concentration reveals the great impact and influence of diffusion and adsorption site on removal percentage. Curve portion in 3D plot Figure 8 suggested that significant removal of dye was found to have almost good interactive influence of these two variables.

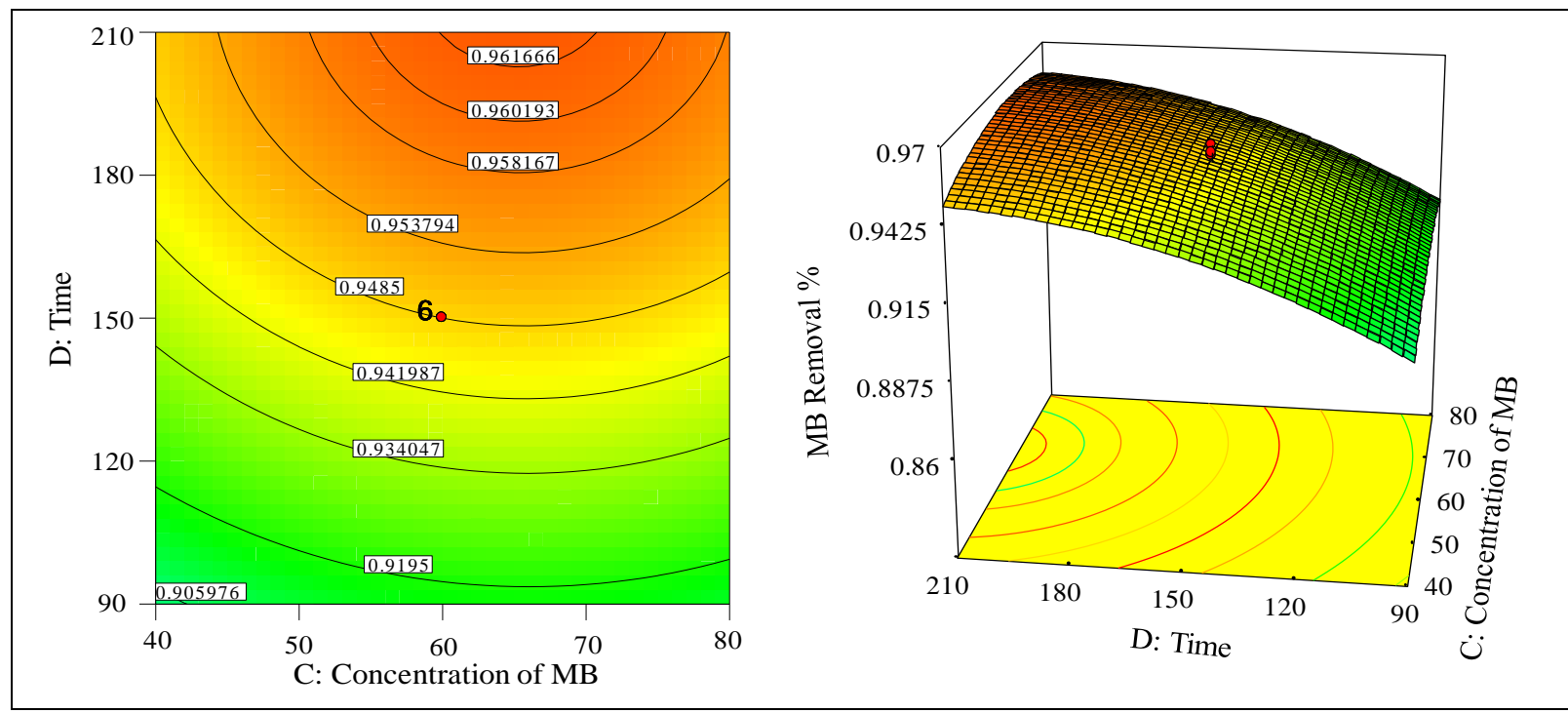

Figure 9. The response surface plots (left) and their corresponding contour plots (right) showing effect of time and concentration of $\mathrm{MB}$ for the removal of $\mathrm{MB}$

\subsubsection{Model Validation for MB Dye}

The validation experiment was performed by several sets of different combination of variables ( $\mathrm{pH}$, adsorbent dosage, MB concentration and time) each within their experimental ranges. The model predicated value and experimental value were used to determine the validity of model (Table 4). The fact that the estimated results properly agree with the empirical amounts is approved by these results.

Table 4. Comparing the experimental and predicted values.

\begin{tabular}{|c|c|c|c|c|c|c|}
\hline \multirow{2}{*}{ Run No. } & \multirow{2}{*}{ pH } & \multirow{2}{*}{$\begin{array}{l}\text { adsorbent dosage } \\
\qquad\left(\mathrm{g} \mathrm{L}^{-1}\right)\end{array}$} & \multirow{2}{*}{$\begin{array}{l}\text { MB concentration } \\
\quad\left(\mathrm{mg} \mathrm{L}^{-1}\right)\end{array}$} & \multirow{2}{*}{$\begin{array}{l}\text { Time } \\
(\min )\end{array}$} & \multicolumn{2}{|c|}{ MB removal } \\
\hline & & & & & Experimental $^{\text {a }}$ & Predicted \\
\hline 1 & 7 & 0.2 & 30 & 80 & $0.815 \pm 0.026$ & 0.772 \\
\hline 2 & 8.5 & 0.35 & 50 & 140 & $0.862 \pm 0.074$ & 0.839 \\
\hline 3 & 10.5 & 0.4 & 75 & 200 & $0.936 \pm 0.053$ & 0.863 \\
\hline
\end{tabular}

On the basis of best fitted equation, the model optimization of variables was done to get the maximum removal percentage. 17 optimized results were obtained and it was found that the maximum optimized conditions for MB dye ( $\mathrm{pH}$ 9.84, adsorbent dosage $4.38 \mathrm{~g} \mathrm{~L}^{-1}, \mathrm{MB}$ concentration $75.50 \mathrm{~g} \mathrm{~L}^{-1}$ and time $208.13 \mathrm{~min}$ ) which showed $98.05 \%$ removal of $\mathrm{MB}$.

\section{Adsorption Kinetics}

The research regarding kinetic adsorption was done in order to describe the dynamics of the process of adsorption in connection with the rate constant's order. Various kinetic models are accessible in order to find out the function of the adsorbent and also to analyze the controlling mechanism of the process of adsorption. In the research the pseudo-first order, pseudo-second order, Elovich and intraparticle diffusion models have been tested for the adsorption of MB onto the adsorbent.

The kinetic parameters of pseudo-first order and pseudo second order were determined from the respective plots at $100 \mathrm{mg} \mathrm{L}^{-1}$ initial concentration of the MB (Table 5). On careful analysis data illustrated that adsorption process agrees with pseudo second order model with $\mathrm{R}^{2}$ value near unity $\left(\mathrm{R}^{2}\right.$ around 0.999$)$. The experimental $\mathrm{q}_{\mathrm{e}}$ of the pseudo first order model did not follow the calculated value, which show failure and inability of this model for fitting data. 
Also, more accurate values of $\mathrm{q}_{\mathrm{e}}$ are found in pseudo second order model which specifies that the process of adsorption is restrained by chemisorption. Chemisorption is the share of electrons or the exchange of them among the dye molecules and the active sites on the adsorbents [43, 44].

In similar studies pseudo second order was reported as the appropriate kinetic model in the adsorption of reactive dye on magnetic composite of activated carbon and iron oxide and in removal of Direct Blue color-06 using activated carbon $[45,46]$.

In order to model the mass transfer resistance that is related to the adsorption which is under research, the Intraparticle diffusion and Elovich models were applied. The amounts of Intraparticle diffusion rate constant $\left(\mathrm{K}_{\mathrm{id}}\right)$ is computed from the slope of the curve. The amounts of $\mathrm{R}^{2}, \mathrm{~K}_{\mathrm{id}}$ and intercept are presented in Table 5. The amounts of $\mathrm{R}^{2}$ for this diffusion model were 0.991 that also shows the probability of in mass transfer and adsorption rate. The intercepts propose an opinion about the thickness of the boundary layer. The larger the intercept is equal to greater value of boundary layer effect. The Elovich constants can be calculated from the plots of $\mathrm{q}_{\mathrm{t}}$ versus $\ln \mathrm{t}$ and regarding this matter the small amounts of $\mathrm{R}^{2}$ (the correlation coefficient) verifies that the model is not suitable for MB's adsorption by the adsorbent (Table 5).

Table 5. Kinetic parameters removal of MB

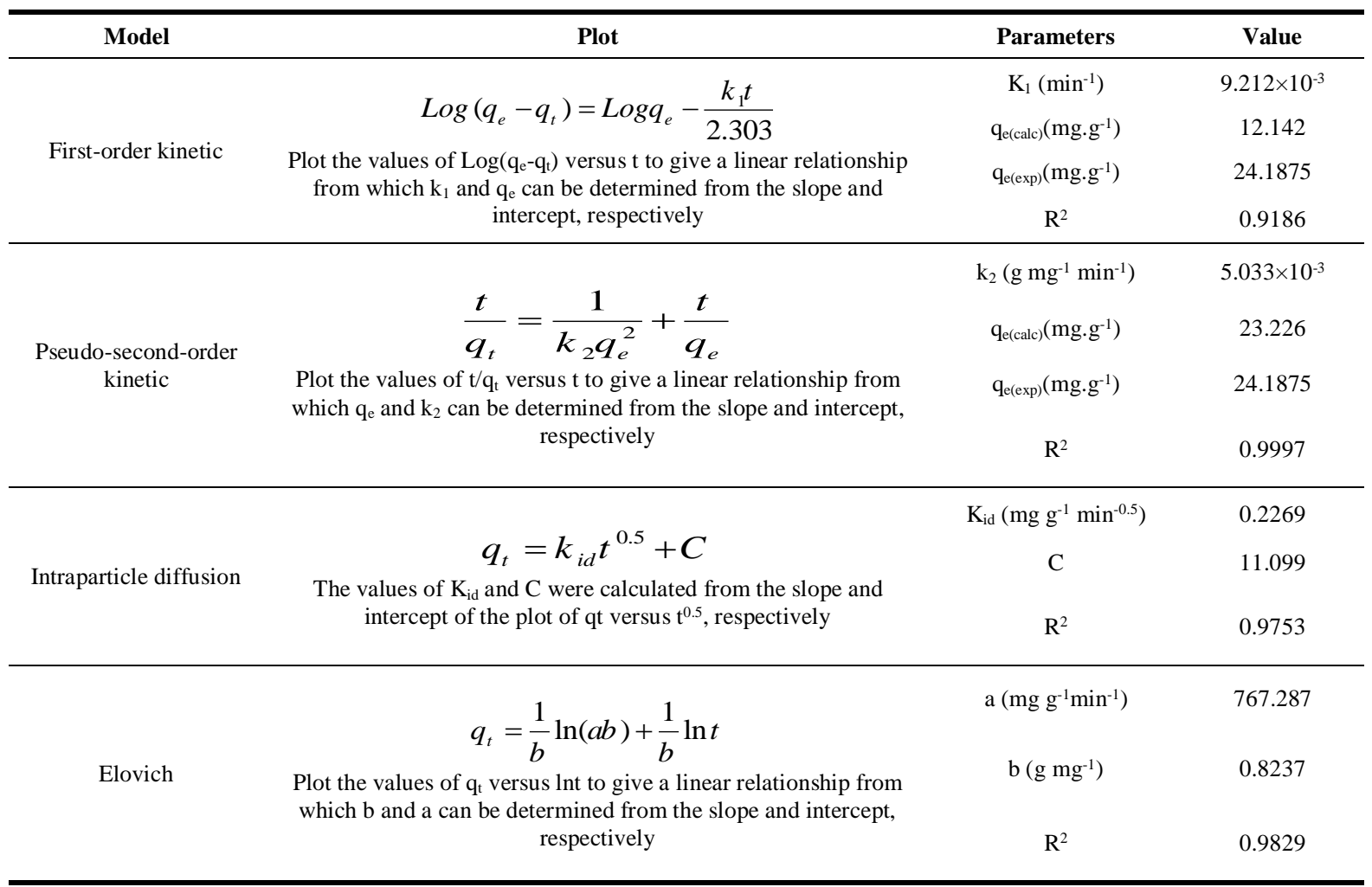

\section{Adsorption Equilibrium Study}

The adsorption isotherm studies were conducted the adsorption system (MB dye solution and Cellulose dusts) at the optimum conditions (initial MB concentration: 20-100 mg L-1, $\mathrm{pH}$ of 11, adsorbent mass $4.4 \mathrm{~g} \mathrm{~L}^{-1}$, time of 210 min at $25^{\circ} \mathrm{C}$ ). Passing of time makes the system to finally reach equilibrium. After reaching that state, the mixture was centrifuged in order to distinct the supernatant and spent adsorbent. Various isotherms regarding adsorption (Langmuir, Freundlich, Temkin and Harkins-Jura models) were applied to investigate the empirical equilibrium data of the adsorption of dye. Their constant factors and the correlation coefficient $\left(\mathrm{R}^{2}\right)$ were computed which are presented in Table 6.

The amounts of $\mathrm{K}_{\mathrm{L}}$ which represents the Langmuir adsorption constant $\left(\mathrm{L} \mathrm{mg}^{-1}\right)$ and $\mathrm{q}_{\mathrm{o}}$ which stands for theoretical maximum adsorption capacity $\left(\mathrm{mg} \mathrm{g}^{-1}\right)$ were attained from the intercept and slope of the plot of $\mathrm{C}_{\mathrm{e}} / \mathrm{q}_{\mathrm{e}} \mathrm{vs}$. $\mathrm{C}_{\mathrm{e}}$, respectively.

In fit best in freundlich isotherms model, this implies that the adsorption heat of all molecules drops linearly with the rise in the adsorbent surface occupancy. It also proposes that the properties of adsorptions be determined by a homogenous distribution of binding energies up to the time that a threshold binding energy is gained [47]. Same results were attained in the adsorbtion of methylene blue on to date palm leaves [48]. The parameters of Freundlich isotherm model like $\mathrm{k}_{\mathrm{F}}\left(\left(\mathrm{mg} \mathrm{g}^{-1}\right)\right)\left(\left(\mathrm{mg} \mathrm{L}^{-1}\right)\right)$ and $\mathrm{n}$ (which represents the adsorption's intensity and capacity) were computed from the intercept and slope of the linear plot of $\ln \mathrm{q}_{\mathrm{e}} \mathrm{vs} \ln$ Ce respectively. 
The heat of the adsorption and the adsorbent adsorbate interaction were evaluated by using temkin isotherm model. Parameters of the model are as follows: B represents the temkin constant corresponding to the adsorption's heat ( $\mathrm{j} \mathrm{mol}{ }^{-}$ $\left.{ }^{1}\right)$, $\mathrm{T}$ stands for the absolute temperature $(\mathrm{K})$, $\mathrm{R}$ denotes the universal gas constant $\left(8.314 \mathrm{~J} \mathrm{~mol}^{-1} \mathrm{~K}^{-1}\right)$ and $\mathrm{K}_{\mathrm{T}}$ is the equilibrium binding constant $\left(\mathrm{L} \mathrm{mg}^{-1}\right)$.

Harkins Jura Isotherm model has the assumption of the heterogeneous surface and explains the multilayer adsorption of the adsorbate onto the adsorbent's surface. The values of the respective model constants were obtained from the slope and intercept of the plot between $\log \mathrm{C}_{\mathrm{e}}$ and $1 / \mathrm{q}_{\mathrm{e}}{ }^{2}$ as presented in Table 6 .

The experimental results show that the Harkins-Jura Isotherm model was well followed by CD adsorbent for removal of $\mathrm{MB}$ and the $\mathrm{R}^{2}$ value was observed to be 0.857 as shown in Table 6 .

Table 6. Isotherm constant parameters and correlation coefficients calculated for removal of MB

\begin{tabular}{|c|c|c|c|}
\hline Isotherm & Equation & Parameters & Value \\
\hline \multirow{3}{*}{ Langmuir } & $C_{e} C_{e}$ & $\mathrm{~K}_{\mathrm{L}}$ & 0.04185 \\
\hline & $\begin{array}{c}q_{e} \overline{q_{o}} \overline{K_{L} q_{o}} \\
\text { A plot } \mathrm{C}_{c} / \mathrm{g}_{\mathrm{e}} \text { versus } \mathrm{C}_{e} \text { should indicate a straight line of slope } 1 / \mathrm{q}_{\mathrm{a}} \text { and an }\end{array}$ & $\mathrm{q}_{\mathrm{o}}$ & 153.85 \\
\hline & intercept of $1 /\left(\mathrm{K}_{\mathrm{L}} \mathrm{q}_{\mathrm{o}}\right)$ & $\mathrm{R}^{2}$ & 0.4174 \\
\hline \multirow{3}{*}{ Freundlich } & 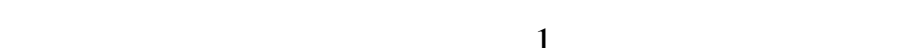 & $\mathrm{K}_{\mathrm{F}}$ & 6.285 \\
\hline & & $\mathrm{n}$ & 1.102 \\
\hline & plot of $\ln \mathrm{q}_{\mathrm{e}}$ versus $\ln \mathrm{C}_{\mathrm{e}}$, respectively & $\mathrm{R}^{2}$ & 0.993 \\
\hline \multirow{3}{*}{ Temkin } & & A & 1.827 \\
\hline & $q_{e}=B \ln A+B \ln C_{e}$ & B & 10.39 \\
\hline & & $\mathrm{R}^{2}$ & 0.916 \\
\hline \multirow{3}{*}{ Harkins-Jura } & $1 \quad B_{H} \quad 1$ & A & 17.857 \\
\hline & $\overline{q_{e}^{2}}=\frac{\Pi}{A}-\bar{A} \log C_{e}$ & $\mathrm{~B}_{\mathrm{H}}$ & 0.543 \\
\hline & Values of $A$ and $B_{H}$ were calculated from the plot of $1 / \mathrm{q}_{e}^{2}$ against $\log C_{e}$ & $\mathrm{R}^{2}$ & 0.857 \\
\hline
\end{tabular}

\section{Conclusion}

Cellulose Dusts is a low-cost and efficient adsorbent for the removal of methylene blue from aqueous solutions. The CD properties was determined by FTIR, SEM and XRD. RSM based CCD was carried out for optimization of variable factors like the duration of contact, agitation speed, the dose of adsorbent, $\mathrm{pH}$ and $\mathrm{MB}$ initial concentration. The optimum conditions for MB removal were $\mathrm{MB}$ concentration of $75.50 \mathrm{~g} \mathrm{~L}^{-1}, \mathrm{pH} 9.84$, adsorbent dosage $4.38 \mathrm{~g} \mathrm{~L}^{-1}$ and time 208.13 min, where $98.05 \%$ of MB removal could be obtained from the proposed model. The data which was obtained from the equilibrium state was satisfactorily in agreement with Freundlich isotherm equations $\left(\mathrm{R}^{2}=0.99\right)$. It was concluded that the adsorption rate was close agreement with the pseudo-second-order model and had an acceptable correlation coefficient. Intraparticle diffusion model's results proposed that the methylene blue's adsorption on CD is a process consisting several steps which includes sorption on the external surface and also diffusion inside the adsorbent. Our results taken together show that $\mathrm{CD}$ an interesting low-cost adsorbent candidate for the removal of methylene blue from aqueous solutions

\section{References}

[1] Shukla, S.P., Singh, A., Dwivedi, L., Sharma, K.J., Bhargava, D.S., Shukla, R., Singh, N.B., Yadav, V.P., Markandeya. "Minimization of contact time for two-stage batch adsorber design using second-order kinetic model for adsorption of methylene blue (MB) on used tea leaves." International Journal of Innovation Science and Research 2.1 (2014): 58-66, https://doi.org/ 10.13140/RG.2.1.2225.2644.

[2] Barragán, B.E., Costa, C., Márquez, M. C. "Biodegradation of azo dyes by bacteria inoculated on solid media.” Dyes and Pigments 75.1 (2007): 73-81, https://doi.org/10.1016/j.dyepig.2006.05.014.

[3] Abidi, N., Errais, E., Duplay, J., Berez, A., Jrad, A., Schafer, G., Ghazie, M., Semhif, K., Trabelsi-Ayadi, M. "Treatment of dyecontaining effluent by natural clay.” Journal of cleaner production 86 (2015): 432-440, https://doi.org/10.1016/j.jclepro.2014.08.043.

[4] Daneshvar, N., Khataee, A.R. "Removal of azo dye C.I. acid red 14 from contaminated water using Fenton, UV/H2O2, $\mathrm{UV} / \mathrm{H} 2 \mathrm{O} 2 / \mathrm{Fe}(\mathrm{II}), \mathrm{UV} / \mathrm{H} 2 \mathrm{O} 2 / \mathrm{Fe}$ (III) and UV/H2O2/Fe(III)/oxalate processes: a comparative study." Journal of Environmental Science and Health, Part A 41 (2006): 315-328. https://doi.org/10.1080/10934520500423196. 
[5] Pham, T.D., Kobayashi, M., Adachi, Y. "Adsorption characteristics of anionic azo dye onto large alumina beads." Colloid and Polymer Science 293 (2015): 1877-1886, https://doi.org/10.1007/s00396-015-3576-x.

「6] Forgacs, E., Cserhati, T., Oros, G. "Removal of synthetic dyes from wastewaters: a review." Environment International 30 (2004): 953-971, https://doi.org/10.1016/j.envint.2004.02.001.

[7] Moreira, F.C., Garcia-Segura, S., Vilar, V.J.P., Boaventura, R.A.R., Brillas, E. "Decolorization and mineralization of Sunset Yellow FCF azo dye by anodic oxidation, electro-Fenton, UVA photoelectro-Fenton and solar photoelectroFenton processes." Applied. Catalysis B: Environmental 142 (2013): 877-890, https://doi.org/10.1016/j.apcatb.2013.03.023.

「81 Dogan. M., Alkan, M., Onganer, Y. "Adsorption of methylene blue from aqueous solution onto perlite." Water, Air and Soil Pollution 120 (2000): 229 248, https://doi.org/10.1023/A:1005297724304.

[9] Eskizeybek, V., Sar, F., H. Gülce, A. Gülce, A. Avc, "Preparation of the new polyaniline/ZnO nanocomposite and its photocatalvtic activitv for degradation of methvlene blue and malachite green dves under UV and natural sun lights irradiations." Applied Catalysis B 119.120 (2012): 197-206, https://doi.org/10.1016/j.apcatb.2012.02.034.

[10] Wang, C., Wang, F., Xu, M., Zhu, C., Fang, W., Wei, Y. "Electrocatalytic degradation of methylene blue on Co doped Ti/TiO2 nanotube/PbO2 anodes prepared bv pulse electrodenosition." Journal of Electroanalvtical Chemistrv 759 (2015): 158-166. https://doi.org/10.1016/j.jelechem.2015.11.009.

[11] Asfaram, A., Ghaedi, M., Azqhandi, M.H.A., Goudarzi, A., Dastkhoon, M. "Statistical experimental design, least squaressupport vector machine (LS-SVM) and artificial neural network (ANN) methods for modeling the facilitated adsorption of methvlene blue dye." RSC Advances 6(2016): 40502-40516, https://doi.org/10.1039/C6RA01874B.

「121 Mukheriee. K.. Kedia. A.. Jagaiianani. Rao. K.. Dhir. S.. Paria. S. "Adsorntion enhancement of methvlene blue dve at kaolinite clay-water interface influenced by electrolyte solutions.” RSC Advances 5 (2015): 30654 30659, doi: 10.1039/C5RA03534A.

[13] Katuri, K.P., Mohan, S.V., Sridhar, S., Pati, B.R., Sarma, P.N. "Laccasemembrane reactors for decolorization of an acid azo dye in aqueous phase: process optimization.” Water Research 43(2009): 3647-3658, https://doi.org/10.1016/j.watres.2009.05.028.

$\lceil 141$ Geckeler. K.F. Volchek. K.. "Removal of hazardous substances from water using ultrafiltration in coniunction with soluh le polymers.” Environmental Science Technology 30.3 (1996): 725-734, https://doi.org/10.1021/es9503261.

[15] Arslan-Alaton, I., Tureli, G., Olmez-Hanci, T. "Treatment of azo dye production wastewaters using Photo-Fenton-like advanced nxidation nrocesses - nntimization hv resnonse surface methodoloov" Inurnal of Photochemistrv and Photohinloov A. Chemistrv 202.2 (2009): 142-153, https://doi.org/10.1016/j.jphotochem.2008.11.019.

「1617.n H Ma W Wano Y “A novel nrocess of dve wastewater treatment hv linkino advanced chemical nxidation with hiolocical oxidation.” Archives of Environmental Protection 41.4 (2015): 33-39, https://doi.org/10.1515/aep-2015-0037.

「171 Karcher. S.. Kornmuller. A.. Jekel. M. "Anion exchange resins for removal of reactive dves from textile wastewaters.” Water Research 36 (2002): 4717-4724, https://doi.org/10.1016/S0043-1354(02)00195-1.

[18] Morshedi, D., Mohammadi, Z., Boojar, M.M.A., Aliakbari, F., 2013. "Using protein nanofibrils to remove azo dyes from aqueous solution hv the coapulation nrocess." Colloids and Surfaces B: Bininterfaces 112 (2013): 245-254 https://doi.org/10.1016/j.colsurfb.2013.08.004.

[19] Markandeya, Singh, A., Shukla, S.P., Mohan, D., Singh, N.B., Bhargava, D.S., Shukla, R., Pandey, G., Yadav, V.P., Kisku, G.C. "Adsorntive canacitv of sawdust for the adsorntion of MR dve and desioning of two-stage hatch adsorher" Cooent Fnvironmental Science 1.1 (2015): 1-16, https://doi.org/10.1080/23311843.2015.1075856.

[20] Asfaram, A., Ghaedi, M., Hajati, S., Rezaeinejad, M., Goudarzi, A., Purkait, M.K., "Rapid removal of Auramine-O and Methvlene blue bv ZnS: Cu nanonarticles loaded on activated carbon: a resnonse surface methodologv annroach." Journal of the Taiwan Institute of Chemical Engineers 53 (2015): 80-91, https://doi.org/10.1016/j.jtice.2015.02.026.

[21] Amin, N.K., "Removal of Direct Blue-106 dye from aqueous solution using new activated carbons developed from pomegranate neel: adsorntion equilibrium and kinetics." Journal of Hazardous Materials 165 (2009): 52 62 https://doi.org/10.1016/j.jhazmat.2008.09.067.

[22] Wang, S., Zhu, Z.H., Coomes, A., Haghseresht, F., Lu, G.Q. "The physical and surface chemical characteristics of activated carhons and the sorntion of methvlene hlue from wastewater." Iournal of Colloid and Interface Science 284 (2005): 440-446 https://doi.org/10.1016/j.jcis.2004.10.050.

$\lceil 231$ Hameed. B.H. "Grass Waste: a novel sorbent for the removal of basic dve from aqueous solution.” Journal of Hazardous Materials 166 (2009): 233-238, https://doi.org/10.1016/j.jhazmat.2008.11.019.

[24] Arslan-Alaton, I., Tureli, G., Olmez-Hanci, T. "Treatment of azo dye production wastewaters using Photo-Fenton-like advanced oxidation processes: optimization by response surface methodology." Journal of Photochemistry and Photobiology A: Chemistry 202.2 (2009): 142-153, https://doi.org/10.1016/j.jphotochem.2008.11.019.

[25] Sharma, S., Malik, A., Satya, S. "Application of response surface methodology (RSM) for optimization of nutrient supplementation for Cr (VI) removal by Aspergillus lentulus AML05.” Journal of Hazardous Materials 164.2.3 (2009): 1198-1204, https://doi.org/10.1016/j.jhazmat.2008.09.030. 
[26] Ghaedi, M., Khafri, H.Z., Asfaram, A., Goudarzi, A. "Response surface methodology approach for optimization of adsorption of Janus Green B from aqueous solution onto $\mathrm{ZnO} / \mathrm{Zn}(\mathrm{OH}) 2-\mathrm{NP}-\mathrm{AC}$ : kinetic and isotherm study." Spectrochimica Acta Part A: Molecular and Biomolecular Spectroscopy 152 (2016): 233-240, https://doi.org/10.1016/j.saa.2015.06.128.

[27] Langmuir, I. "The adsorption of gases on plane surfaces of glass, mica and platinum." Journal of the American Chemical Society 40(1918): 1361-1403. https://doi.org/10.1021/ja02242a004.

[28] Freundlich, H.M.F. “Over the adsorption in solution.” The Journal of Physical Chemistry 57(1906): 385-470.

[29] Asfaram, A., Ghaedi, M., Hajati, S., Reza einejad, M., Goudarzi, A., Purkait, M.K. "Rapid removal of Auramine-O and Methylene blue by $\mathrm{ZnS}: \mathrm{Cu}$ nanoparticles." Journal of the Taiwan Institute of Chemical Engineers 53 (2015): 80-91, https://doi.org/10.1016/j.jtice.2015.02.026.

[30] Khodadoust, S., Ghaedi, M., Hadjmohammadi, M.R. "Dispersive nano Solid material-ultrasound assisted microextraction as a novel method for extraction and determination of bendiocarb and promecarb: Response Surface Methodology." Talanta 116 (2013): 637-646. https://doi.org/10.1016/j.talanta.2013.07.013.

[31] Ciolacu, D., Ciolacu, F. and Popa, V. I. "Amorphous Cellulose-Structure and Characterization.” Cellulose Chemistry and Technology 45.1.2 (2011): 13-21.

[32] Sharifi Pajaie, H., Taghizadeh, M. "Methanol conversion to light olefins over surfactant modified nanosized SAPO-34." Reaction Kinetics, Mechanisms and Catalysis 118.2 (2016): 701-717, https://doi.org/10.1007/s11144-016-1023-8.

[33] Ahmad, A., Khatoon, A., Mohd-Setapar, S.H., Kumar, R., Rafatullah, M. "Chemically oxidized pineapple fruit peel for the biosorption of heavy metals from aqueous solutions." Desalination and Water Treatment 57 (2016) 6432-6442, https://doi.org/10.1080/19443994.2015.1005150.

[34] Yagub, M.T., Sen, T.K., Afroze, S., Ang, H.M., "Fixed-bed dynamic column adsorption study of methylene blue (MB) onto pine cone." Desalination and Water Treatment 55 (2015): 1026 1039, https://doi.org/10.1080/19443994.2014.924034.

[35] Pehlivan, H.T., Tran, W.K., Ouédraogo, C., Schmidt, D., Zachmann, M. "Sugarcane bagasse treated with hydrous ferric oxide as a potential adsorbent for the removal of As (V) from aqueous solutions." Food Chemistry 138 (2013): 133-138, https://doi.org/10.1016/j.foodchem.2012.09.110.

[36] Pavan, F.A., Lima, E.C., Dias, S.L.P., Mazzocato, A.C. "Methylene blue biosorption from aqueous solutions by yellow passion fruit waste." Journal of Hazardous Materials 150 (2008): 703-712, https://doi.org/10.1016/j.jhazmat.2007.05.023.

[37] Feng, N., Guo, X. "Characterization of adsorptive capacity and mechanisms on adsorption of copper, lead and zinc by modified orange peel." Transactions of Nonferrous Metals Society of China 22 (2012): 1224-1231, https://doi.org/10.1016/S10036326(11)61309-5.

[38] Singh, J., Ali, A., Jaswal, V.S., Prakash, V. "Desalination of $\mathrm{Cd} 2+$ and $\mathrm{Pb} 2+$ from paint industrial wastewater by aspergillus niger decomposed citrus limetta peel powder." International Journal of Environmental Science and Technology 12 (2015): 25232532, https://doi.org/10.1007/s13762-014-0620-1.

[39] Deniz, F., Kepekci, R.A. "Dye biosorption onto pistachio by-product: a green environmental engineering approach.” Journal of Molecular Liquids 219 (2016): 194-200, https://doi.org/10.1016/j.molliq.2016.03.018.

[40] Dil, E.A., Ghaedi, M., Ghaedi, A.M., Asfaram, A., Goudarzi, A., Hajati, S., Soylak, M., Agarwal, Gupta, S. V.K. "Modeling of quaternary dyes adsorption onto $\mathrm{ZnO}-\mathrm{NR}-\mathrm{AC}$ artificial neural network: analysis by derivative spectrophotometry." Journal of Industrial and Engineering Chemistry 34 (2016) 186-197, https://doi.org/10.1016/j.jiec.2015.11.010.

[41] Dogar, C., Gurses, A., Ackkylldı, M., Ozkan, E. "Thermodynamics and kinetic studies of biosorption of a basic dye from aqueous solution using green algae Ulothrix sp." Colloids Surfaces B Biointerfaces 76 (2010): 279-285, https://doi.org/10.1016/j.colsurfb.2009.11.004.

[42] Kumar, A., Prasad, B., Mishra, I.M. "Optimization of process parameters for acrylonitrile removal by a low-cost adsorbent using BoxeBehnken design Journal of Hazardous Materials.” 150 (2008): 174-182, https://doi.org/10.1016/j.jhazmat.2007.09.043.

[43] Kakavandi, B., Esrafili, A., Mohseni-Bandpi, A., Jafari, A.J., Kalantary, R.R. "Magnetic Fe3O4@C nanoparticles as adsorbents for removal of amoxicillin from aqueous solution." Water Science Technology 69 (2014): 147-155, https://doi.org/10.2166/wst.2013.568.

[44] Hu, X.J., Liu, Y.G., Wang, H., Chen, A.W., Zeng, G.M., Liu, S.M., Guo, Y.M., Hu, X., Li, T.T., Wang, Y.Q., Zhou, L., Liu, S.H. "Removal of $\mathrm{Cu}(\mathrm{II})$ ions from aqueous solution using sulfonated magnetic graphene oxide composite." Separation and Purification Technology 108 (2013): 189-195, https://doi.org/10.1016/j.seppur.2013.02.011.

[45] Rezaei Kalantry, R., Jonidi Jafari, A., Esrafili, A., Kakavandi, B., Gholizadeh, A., Azari, A. "Optimization and evaluation of reactive dye adsorption on magnetic composite of activated carbon and iron oxide." Desalination and Water Treatment 57 (2016): 6411-6422, https://doi.org/10.1080/19443994.2015.1011705.

[46] Amin, N.K. "Removal of reactive dye from aqueous solutions by adsorption onto activated carbons prepared from sugarcane bagasse pith.” Desalination 223 (2008): 152-161, https://doi.org/10.1016/j.desal.2007.01.203.

[47] Piccin, J.S., Dotto, G.L., Pinto, L.A.A. “Adsorption isotherms and thermochemical data of FD and C RED no 40 binding by 
chitosan.” Brazilian Journal of Chemical Engineering 28 (2011): 295-304, http://dx.doi.org/10.1590/S0104-66322011000200014.

[48] Gouamid, M., Ouahrani, M.R., Bensaci, M.B. "Adsorption equilibrium, kinetics and thermodynamics of methylene blue from aqueous solutions using Date Palm Leaves.” Energy Procedia 36 (2013): 898-907, http://dx.doi.org/ 10.1016/j.egypro.2013.07.103. 